\title{
Solubilization of Polyelectrolytic Hairy-Rod Polyfluorene in Aqueous Solutions of Nonionic Surfactant
}

\author{
Matti Knaapila, ${ }^{*} \dagger$ László Almásy, ${ }^{*}$ Vasil M. Garamus, ${ }^{\S}$ Christopher Pearson, ${ }^{\perp}$ \\ Swapna Pradhan," Michael C. Petty, ${ }^{\perp}$ Ullrich Scherf," Hugh D. Burrows, ${ }^{\#}$ and \\ Andrew P. Monkman ${ }^{\dagger}$ \\ Department of Physics, University of Durham, South Road, Durham DH1 3LE, United Kingdom, Research \\ Institute for Solid State Physics and Optics, P.O. Box 49, Budapest-1525, Hungary, GKSS Research Centre, \\ Max-Planck-Strasse 1, D-21502 Geesthacht, Germany, School of Engineering, University of Durham, \\ South Road, Durham DH1 3LE, United Kingdom, Makromolekulare Chemie und Institut für \\ Polymertechnologie, Gauss-Str. 20, Bergische Universität Wuppertal, D-42097 Wuppertal, Germany, and \\ Departamento de Química, Universidade de Coimbra, P-3004-535 Coimbra, Portugal
}

Received: October 22, 2005; In Final Form: March 24, 2006

\begin{abstract}
We report on the solubilization, phase behavior, and self-organized colloidal structure of a ternary waterpolyfluorene-surfactant (amphiphile) system comprised of polyelectrolytic poly\{1,4-phenylene[9,9-bis(4phenoxybutylsulfonate)]fluorene-2,7-diyl\} (PBS-PFP) in nonionic pentaethylene glycol monododecyl ether $\left(\mathrm{C}_{12} \mathrm{E}_{5}\right)$ at $20^{\circ} \mathrm{C}$. We show in particular how a high amount (milligrams per milliliter) of polyfluorene can be solubilized by aqueous $\mathrm{C}_{12} \mathrm{E}_{5}$ via aggregate formation. The PBS $-\mathrm{PFP}$ and $\mathrm{C}_{12} \mathrm{E}_{5}$ concentrations of $0.31 \times$ $10^{-4}-5 \times 10^{-4} \mathrm{M}$ and $2.5 \times 10^{-4}-75 \times 10^{-4} \mathrm{M}$, respectively, were used. Under the studied conditions, the photoluminescence (PL), surface tension, static contact angle, and $(\pi-A)$ isotherm measurements imply that $\mathrm{D}_{2} \mathrm{O}-\mathrm{PBS}-\mathrm{PFP}\left(\mathrm{C}_{12} \mathrm{E}_{5}\right)_{x}$ realizes three phase regimes with an increasing molar ratio of surfactant over monomer unit $(x)$. First, for $x \leq 0.5$, the mixture is cloudy. In this regime polymer is only partially dissolved. Second, for $1 \leq x \leq 2$, the solution is homogeneous. In this regime polymer is dissolved down to the colloidal level. Small-angle neutron scattering (SANS) patterns indicate rigid elongated (polymer-surfactant) aggregates with a diameter of $30 \AA$ and mean length of $\sim 900 \AA$. The ratio between contour length and persistence length is less than 3. Third, for $x \geq 4$, the solution is homogeneous and there is cooperative binding between polymer and surfactant. Surface tension, contact angle, and surface pressure remain essentially constant with increasing $x$. A PL spectrum characteristic of single separated polyfluorene molecules is observed. SANS curves show an interference maximum at $q \sim 0.015 \AA^{-1}$, indicating an ordered phase. This ordering is suggested to be due to the electrostatic repulsion between polymer molecules adsorbed on or incorporated into the $\mathrm{C}_{12} \mathrm{E}_{5}$ aggregates (micelles). On dilution the distance between micelles increases via 3-dimensional packing. In this regime the polymer is potentially dissolved down to the molecular level. We show further that the aggregates $(x=2)$ form a floating layer at the air-water interface and can be transferred onto hydrophilic substrates.
\end{abstract}

\section{Introduction}

There are myriad reasons to develop water soluble $\pi$-conjugated polymers and tailor their phase behavior, structure, and supramolecules in water. Water soluble $\pi$-conjugated polymers form an option for interrogating biological substrates. ${ }^{1,2}$ The inkjet process and layer-by-layer self-assembly-the major advantages of polymers over oligomers in light emitting diode (LED) fabrication-benefit from electroluminescent materials in nonnoxious solvent, harmless for the cartridges. ${ }^{3}$ A tuning of the air-water interface of $\pi$-conjugated polymers ${ }^{4}$ is a base of Langmuir-Blodgett (LB) films ${ }^{5}$ having opportunities in sensors. ${ }^{6}$ Dissolving $\pi$-conjugated "model" polymers in water can also promote general understanding of the self-assembly of $\pi$-conjugated hairy-rod polymers. ${ }^{7}$

* Address correspondence to this author. Phone: +44-191-33-43558 Fax: +44-191-33-43585. E-mail: matti.knaapila@durham.ac.uk.

† Department of Physics, University of Durham.

Research Institute for Solid State Physics and Optics

$\S$ GKSS Research Centre.

${ }^{\perp}$ School of Engineering, University of Durham.

" Bergische Universität Wuppertal.

\# Departamento de Química, Universidade de Coimbra.
Control of the solubility of $\pi$-conjugated polymers is a nontrivial task. Few such polymers can be dissolved in water. A typical strategy to achieve water solution is to introduce neutral or charged hydrophilic functionalities to the terminal position of the polymer backbone. Examples include cationic ${ }^{8,9}$ and sulfonated ${ }^{10}$ poly ( $p$-phenylene) (PPP) and sulfonated poly( $p$-phenylenevinylene) (PPV), poly[5-methoxy-2-(4-sulfoxybutoxy)-1,4-phenylene-vinylene] (MBL-PPV). ${ }^{11}$ Water soluble polyfluorenes (PFs) used in DNA peptide nucleic acid detection $^{12}$ belong to this class of materials. However, the water solubility of PFs is difficult to achieve in high concentrations and cosolvents such as methanol are employed to ensure the uniformity of the solutions. ${ }^{13}$ Another strategy to assist solubility of $\pi$-conjugated polymers is a surfactant layer separating polymer and solvent. The interaction between polymer and surfactant can be due to either hydrophobic-hydrophilic effects ${ }^{14}$ or strong physical bonds. ${ }^{15}$ Examples include polyelectrolytic PPV ${ }^{16}$ and PF. ${ }^{14,15,17}$ This technique can also be used to induce liquid crystallinity as shown for $\mathrm{PPP}^{18,19}$ and poly(p-pyridine). ${ }^{20}$ 
CHART 1: Chemical Structure of the PBS-PFP Copolymer

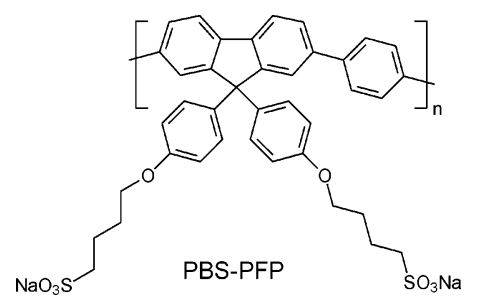

Oxyethylene glycol-monoethers $\left(\mathrm{C}_{i} \mathrm{E}_{j}\right)^{21,22}$ are archetypical surfactants widely used in fundamental phase studies of microemulsions, ${ }^{23-27}$ block-co-polymers, ${ }^{28}$ and micelles. ${ }^{29,30}$ The phase behavior of pentaethylene glycol monododecyl ether ( $n$ dodecyl pentaoxyethylene glycol ether) $\left(\mathrm{C}_{12} \mathrm{E}_{5}\right)^{31,32}$ is particularly well-known: Pure $\mathrm{C}_{12} \mathrm{E}_{5}$ forms cylindrical micelles but the oil-swollen $\mathrm{C}_{12} \mathrm{E}_{5}$ micelles are wormlike with a rather high flexibility and cannot be described as rigid rods. ${ }^{33,30}$

Several $\mathrm{C}_{i} \mathrm{E}_{j} \mathrm{~s}$ can be used to solubilize selected $\mathrm{PPPs}^{34,35}$ and PFs. ${ }^{14,36}$ A particular example ${ }^{14}$ concerns poly $\{1,4-$ phenylene[9,9-bis(4-phenoxybutylsulfonate)]fluorene-2,7-diyl\} copolymer (or PBS-PFP), see Chart 1. PBS-PFP is not water soluble. However, when the concentration of PBS-PFP is $8.3 \times 10^{-6}$ $\mathrm{M}$ and $0-10 \mathrm{~mol}$ of $\mathrm{C}_{12} \mathrm{E}_{5}$ with respect to the polymer's monomer unit $\left(0-6 \times 10^{-4} \mathrm{M}\right)$ are added, the constituents form a transparent solution with optical changes at the threshold surfactant concentration of $5 \times 10^{-5} \mathrm{M}$. This concentration is close to the critical micelle concentration (CMC) of binary aqueous $\mathrm{C}_{12} \mathrm{E}_{5}, 5 \times 10^{-5} \mathrm{M} .^{22}$ It has been further demonstrated how this results in consequent fluorescence enhancement. ${ }^{14}$

In this paper we present a further investigation of the solubilization of an aqueous $\mathrm{PBS}-\mathrm{PFP} / \mathrm{C}_{12} \mathrm{E}_{5}$ mixture at concentrations much higher than those used in the previous study. ${ }^{14} \mathrm{~A}$ feasibility study for thin film formation from a water subphase is also reported. A high PBS-PFP concentration of $5 \times 10^{-4} \mathrm{M}$ (i.e. 10 times that of the earlier study ${ }^{14}$ ) was specifically selected as it might better allow the formation of thin films from water. The studied surfactant concentration regime $\left(2.5 \times 10^{-4}-100 \times 10^{-4} \mathrm{M}\right)$ and temperature $\left(20^{\circ} \mathrm{C}\right)$ would correspond to the $\mathrm{L}_{1}$ phase (notation for isotropic liquid introduced in ref 37 ) of the binary water $-\mathrm{C}_{12} \mathrm{E}_{5}$ system, yet exceeding its CMC.

Three phase regimes with different characteristics were observed by photoluminescence (PL), surface tension, contact angle, and $(\pi-A)$ isotherm measurements. The structural evolution of observed phases was probed by using small-angle neutron scattering (SANS). Ternary $\mathrm{D}_{2} \mathrm{O}-\mathrm{PBS}-\mathrm{PFP}\left(\mathrm{C}_{12} \mathrm{E}_{5}\right)_{x}$ solution proves to be homogeneous when the polymer concentration is $5 \times 10^{-4} \mathrm{M}$ and when the molar ratio of surfactant over monomer, $x$, is around 1 , defining the first phase boundary. The SANS data of the ternary system differ from that of a binary aqueous surfactant. Elongated objects (mean length $\sim 900 \AA$ ) with near circular cross section (diameter $\sim 30 \AA$ ) are seen for $x=1-2$. These objects are stiffer and thinner than $\mathrm{C}_{12} \mathrm{E}_{5}$ micelles in the same concentration regime. This observation indicates aggregate rather than micelle formation in the ternary system. Increasing the surfactant concentration, at $x=4$, an interference maximum appears at $q \sim 0.015 \AA^{-1}$ indicating ordering of the micelles with a characteristic separation distance of $40 \mathrm{~nm}$, defining the second phase boundary. The ordering is suggested to be due to electrostatic repulsion rather than steric hindrance. The ternary aggregates form a floating layer at the air-water interface, which enables thin film formation from water.

\section{Experimental Section}

Materials. The preparation of PBS-PFP $\left(M_{\mathrm{n}}=6.5 \mathrm{~kg} / \mathrm{mol}\right)$ (Chart 1) has been described in refs 14 and 15. For studying the polymer-solvent system, PBS-PFP was dissolved in deuterated dimethyl sulfoxide (DMSO) (>99.8\%; Euriso-top) to a concentration of $1.3 \mathrm{mg} / \mathrm{mL}$. The ternary polymersurfactant-water solutions were prepared with $\mathrm{D}_{2} \mathrm{O}(>99.9 \%$; GOSS Scientific Instruments Ltd) and $\mathrm{C}_{12} \mathrm{E}_{5}$ (Sigma) to form the $\mathrm{D}_{2} \mathrm{O}-\mathrm{PBS}-\mathrm{PFP}\left(\mathrm{C}_{12} \mathrm{E}_{5}\right)_{x}$ system where $x$ is the molar ratio of $\mathrm{C}_{12} \mathrm{E}_{5}$ with respect to the polymer's monomer unit. The concentration of polymer in heavy water is given with respect to monomer units (not with respect to the whole polymer) and it varied from $0.3 \times 10^{-4}$ to $5 \times 10^{-4} \mathrm{M}$ while $x$ varied from 0.5 to 15 corresponding to the surfactant concentration of $\sim 2.5$ $\times 10^{-4}-75 \times 10^{-4} \mathrm{M}$. All samples were prepared by combining $\mathrm{D}_{2} \mathrm{O}$ mixtures of the pure constituents. Stirring for 1 day and ultrasound agitation for $10 \mathrm{~min}$ were used to ensure uniformity of the solutions. To avoid any degradation, fresh surfactant was used and samples were measured within a few days of preparation.

Thin Films. The $(\pi-A)$ isotherms were measured and nominal Langmuir monolayers formed with use of a LB715 Langmuir-Blodgett trough (Molecular Photonics). The samples were spread onto the surface of a pure water subphase with a microliter syringe. The films were compressed at a speed of $9.4 \times 10^{-5}-4.2 \times 10^{-4} \mathrm{~nm}^{2} /(\mathrm{s} \cdot$ molecule $)$, and a dipping speed of $0.080 \mathrm{~mm} / \mathrm{s}$ was used for transfer to solid substrates consisting of (hydrophilic) glass plates or glass plates made highly hydrophobic with a $2 \%$ solution of dimethyldichlorosilane in 1,1,1-trichloroethane (BDH). Silicon wafers were used to provide a parallel set of samples to glass. In every case the temperature was $20 \pm 1{ }^{\circ} \mathrm{C}$.

PL Measurements. PL measurements of solutions were performed with a Jobin-Yvon Fluoromax fluorimeter and quartz cell at $20 \pm 1{ }^{\circ} \mathrm{C}$. The excitation wavelength was $370 \mathrm{~nm}$ and monochromator resolution $1 \mathrm{~nm}$. As the chromophore concentration was constant for the samples studied, the effect of selfabsorption to the peak position could be ignored. PL measurements of films were done on a Jobin-Yvon Fluorolog spectrometer. The excitation wavelength was $350 \mathrm{~nm}$ and monochromator resolution $1 \mathrm{~nm}$. Measurements were carried out either immediately or within 2 days after film preparation and the results were consistent within this period.

Surface Tension Measurements. Surface tension was measured with the microbalance of a LB715 Langmuir-Blodgett trough (Molecular Photonics), using the Wilhelmy plate method at $20 \pm 1{ }^{\circ} \mathrm{C} . \mathrm{D}_{2} \mathrm{O}$ gave a surface tension of $\sigma=72.5 \pm 1.0$ $\mathrm{mN} / \mathrm{m}$, corresponding to that of distilled water. Experiments were repeated at least three times to ensure consistent values.

Contact Angle Measurements. For contact angle measurements, solution drops were studied on glass plates whose surfaces had been made highly hydrophobic with a $2 \%$ solution of dimethyldichlorosilane in 1,1,1-trichloroethane (BDH). Measurements were performed with a horizontal Vickers microscope equipped with a Canon EO5 digital camera at $20 \pm 1{ }^{\circ} \mathrm{C}$. This method gave a contact angle of $88 \pm 0.5^{\circ}$ and $89 \pm 0.5^{\circ}$ for distilled water and $\mathrm{D}_{2} \mathrm{O}$, respectively. Measurements were reproduced several times. The saturation time for wetting was $60 \mathrm{~s}$ for each sample corresponding to that observed for $\mathrm{C}_{12} \mathrm{E}_{5} /$ oil systems on hydrophobic surfaces in ref 38.

SANS Measurements. SANS experiments were made with the Yellow Submarine instrument at the Budapest Neutron 
Centre in Budapest, Hungary, ${ }^{39}$ and with the SANS-1 instrument at the GKSS research center in Geesthacht, Germany. ${ }^{40}$ Several sample-to-detector distances (from 0.7 to $9.7 \mathrm{~m}$ ) and wavelengths (from 5.7 to $11.4 \AA$ ) were employed to cover the range of the magnitude of scattering vectors $q$ from 0.005 to $0.3 \AA^{-1}$. The wavelength resolution of the Yellow Submarine is 20\% (fullwidth at half-maximum) while that of the SANS-1 is $10 \%$. Hellma quartz cells with $5 \mathrm{~mm}$ path length were filled with the sample solution and placed in a thermostated holder, kept at $20.0 \pm 0.5{ }^{\circ} \mathrm{C}$. The raw spectra were corrected for sample transmission, room background, and sample cell scattering by conventional procedures. ${ }^{41}$ The $2 \mathrm{D}$ isotropic scattering patterns were azimuthally averaged, converted to an absolute scale, and corrected for detector efficiency by dividing by the incoherent scattering spectra of $1 \mathrm{~mm}$ thick pure water. The scattering from $\mathrm{D}_{2} \mathrm{O}$ used for the sample preparation was subtracted as a background; the small incoherent scattering due to the protonated surfactant and polymer was disregarded. The data for one sample were collected for $6 \mathrm{~h}$ on average.

\section{Analysis of SANS Data}

Local Structure. The absolute intensity SANS patterns were analyzed by using a model independent indirect Fourier transform method (IFT) developed by Glatter. ${ }^{42}$ Here we considered noninteracting micelles at the $q$-range $0.02-0.3 \AA^{-1}$ and took instrumental resolution into account according to Pedersen. ${ }^{43}$ In the case of elongated particles, the IFT approach allows the decoupling of the model scattering function and fitting the cross-sectional structure at the $q$-regime dominated by local rigidity of aggregates. The asymptotic behavior of the scattering function for $q>1 / l_{\mathrm{p}}$ ( $l_{\mathrm{p}}$ is the persistence length) can be expressed as

$$
I(q)=\frac{\pi}{q} 2 \pi \int_{0}^{\infty} \tilde{p}_{\mathrm{CS}}(r) J_{0}(q r) r \mathrm{~d} r=\frac{\pi}{q} I_{\mathrm{CS}}(q)
$$

where $J_{0}$ is the zeroth-order Bessel function and $I_{\mathrm{CS}}(q)$ is the cross-sectional scattering intensity.

The normalized cross-sectional distance distribution function $\tilde{p}_{\mathrm{CS}}(r)$ is given by

$$
\tilde{p}_{\mathrm{CS}}(r)=\frac{c}{2 \pi M_{\mathrm{L}}} \int \Delta \rho(\mathbf{r}) \Delta \rho\left(\mathbf{r}+\mathbf{r}^{\prime}\right) \mathrm{d} \mathbf{r}^{\prime}
$$

where $\rho$ is the scattering length density, $c$ the overall concentration, and $M_{\mathrm{L}}$ the mass per length, and where the vectors $\mathbf{r}$ and $\mathbf{r}^{\prime}$ are lying in the cross-sectional plane.

From $\tilde{p}_{\mathrm{CS}}(r)$ we calculated the integral parameters of the aggregate cross section. The cross-sectional radius of gyration, $R_{\mathrm{CS}, \mathrm{g}}$, is given by

$$
R_{\mathrm{CS}, \mathrm{g}}=\left[\frac{\int_{0}^{\infty} r^{2} \tilde{p}_{\mathrm{CS}}(r) \mathrm{d} r}{\int_{0}^{\infty} \tilde{p}_{\mathrm{CS}}(r) \mathrm{d} r}\right]^{1 / 2}
$$

In the case of homogeneous cylidrical object $R_{\mathrm{CS}, \mathrm{g}}=2^{-1 / 2} R$, where $R$ is the radius of cross section. The cross-sectional forward scattered intensity $I_{\mathrm{CS}}(0)$ is given by

$$
I_{\mathrm{CS}}(0)=2 \pi \int_{0}^{\infty} \tilde{p}_{\mathrm{CS}}(r) \mathrm{d} r
$$

which allows us to calculate the mass per length, $M_{\mathrm{L}}$ (in units $\mathrm{g} / \mathrm{cm})$, via

$$
M_{\mathrm{L}}=\frac{I_{\mathrm{CS}}(0)}{\Delta \rho_{\mathrm{m}}{ }^{2}}
$$

Overall Size and Flexibility of Aggregates. The length and flexibility of rodlike aggregates were obtained by fitting the scattering curves by two models: stiff and flexible cylinders. In both cases the scattering intensity is written as

$$
I(q) \sim S_{\mathrm{L}}\left(q, L, l_{\mathrm{p}}\right) S_{\mathrm{CS}}\left(q, R_{\mathrm{CS}}\right)
$$

where for the model of flexible cylinders $S_{\mathrm{L}}\left(q, L, l_{\mathrm{p}}\right)$ is the scattering function of a flexible cylinder of contour length $L$ and persistence length $l_{\mathrm{p}}$. Expression $S_{\mathrm{L}}\left(q, L, l_{\mathrm{p}}\right)$ contains the single-cylinder scattering function for a flexible cylinder with excluded-volume effects and is written as

$$
\begin{aligned}
S_{\mathrm{L}}\left(q, L, l_{\mathrm{p}}\right)=\left\{\left[1-\zeta\left(q, L, l_{\mathrm{p}}\right)\right]\right. & S_{\text {chain }}\left(q, L, l_{\mathrm{p}}\right)+ \\
& \left.\zeta\left(q, L, l_{\mathrm{p}}\right) S_{\text {rod }}(q, L)\right\} G\left(q, L, l_{\mathrm{p}}\right)
\end{aligned}
$$

where $S_{\text {chain }}\left(q, L, l_{\mathrm{p}}\right)$ is the scattering function of a flexible (cylindrical) chain with excluded-volume effects, $S_{\text {rod }}(q, L)$ the scattering function of a rod, and $\zeta\left(q, L, l_{\mathrm{p}}\right)$ a crossover function, and where the function $G\left(q, L, l_{\mathrm{p}}\right)$ corrects the crossover region. Detailed expressions can be found in refs 44-46.

In the case of a stiff $\operatorname{rod} S_{\mathrm{L}}\left(q, L, l_{\mathrm{p}}\right)$ reduces to $S_{\mathrm{rod}}(q, L)$, which represents the scattering of an infinitely thin cylinder of length $L$ as

$$
S_{\text {rod }}(q, L)=\frac{2 S i(q L)}{q L} 4 \sin ^{2}\left(\frac{q L / 2}{q^{2} L^{2}}\right)
$$

where $\operatorname{Si}(x)=\int_{0}^{x} t^{-1} \sin t \mathrm{~d} t$.

For some cases, the aggregates could not be modeled by cylindrical cross section. There we used models of elliptical cross section. The scattering function in this case is written as

$$
S_{\mathrm{CS}}(q, A, B)=\frac{2}{\pi} \int_{0}^{\pi / 2}\left(\frac{2 J_{1}(q r(A, B, \theta))}{q r(A, B, \theta)}\right)^{2} \mathrm{~d} \theta
$$

where $J_{1}$ is the first-order Bessel function, $r(A, B, \theta)=\left[A^{2} \sin ^{2} \theta\right.$ $\left.+B^{2} \cos ^{2} \theta\right]^{1 / 2}$, and $A$ and $B$ are the semi-axes of the ellipse. A circular cross section corresponds to $A=B$.

Aggregation Number from Position of Maximum. In the case where an interference maximum is observed in the scattering curves, it is possible to obtain the aggregation number from the position of this maximum. Here, one assumes that the observed maximum corresponds to the (111) planes of a fcc lattice. ${ }^{47}$ Aggregation number $m$ is expressed via maximum position $q_{\max }$ as

$$
m=\frac{1}{4}\left(\frac{2 \pi 3^{1 / 2}}{q_{\max }}\right)^{3} N_{\mathrm{A}} c
$$

where $N_{\mathrm{A}}$ is Avogadro number and $c$ is the concentration of molecules. Knowing the volume of one molecule, the size and volume of the aggregates can be obtained. If the aggregates have strong interaction, this approximation gives similar results to direct modeling. ${ }^{48}$

\section{Results}

Solution Formation. Solution formation was studied by visual inspection. Figure 1 depicts essential visual examples of the solutions. In the studied concentration regimes $\left(0.3 \times 10^{-4}-\right.$ $\left.5 \times 10^{-4} \mathrm{M}\right) \mathrm{PBS}-\mathrm{PFP}$ is not soluble in water but precipitated 


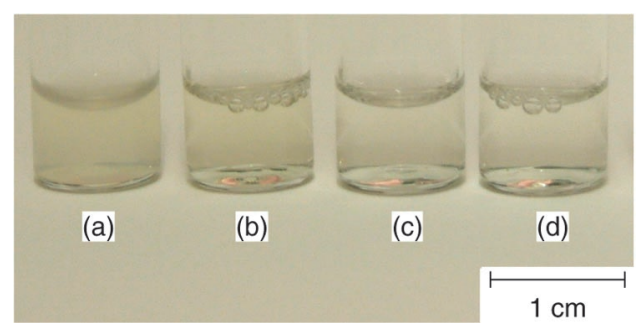

Figure 1. $(\mathrm{a}-\mathrm{d}) \mathrm{A}$ photograph of $\mathrm{D}_{2} \mathrm{O}-\mathrm{PBS}-\mathrm{PFP}\left(\mathrm{C}_{12} \mathrm{E}_{5}\right)_{x}$ for $x=0$, 1,2 , and 10 , respectively, suggesting solution formation. The PBSPFP concentration is $5 \times 10^{-4} \mathrm{M}$ for all $x$.

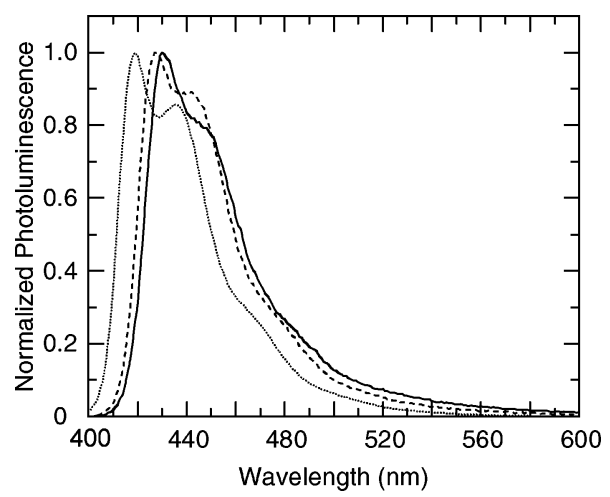

Figure 2. PL spectra of PBS $-\mathrm{PFP}$ (solid line) and PBS $-\mathrm{PFP}\left(\mathrm{C}_{12} \mathrm{E}_{5}\right)_{x}$ for $x=2$ (dashed line) and 8 (dotted line) in $\mathrm{D}_{2} \mathrm{O}$ at $20^{\circ} \mathrm{C}$. The PBSPFP concentration is $5 \times 10^{-4} \mathrm{M}$ for all $x$.

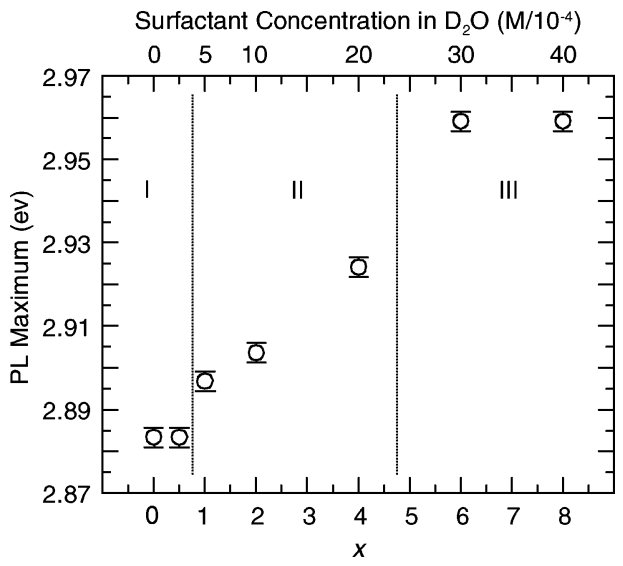

Figure 3. $\mathrm{PL}$ maximum of $\mathrm{D}_{2} \mathrm{O}-\mathrm{PBS}-\mathrm{PFP}\left(\mathrm{C}_{12} \mathrm{E}_{5}\right)_{x}$ as a function of molar ratio $x$ at $20^{\circ} \mathrm{C}$. The PBS-PFP concentration is $5 \times 10^{-4} \mathrm{M}$ for all $x$. The dotted lines distinguish tentative phase regimes I-III.

particles are always observed. Aqueous solutions of pure $\mathrm{C}_{12} \mathrm{E}_{5}$ $\left(2.5 \times 10^{-4}-100 \times 10^{-4} \mathrm{M}\right)$ are naturally transparent. When mixing these constituents we see a clear transition so that PBS$\operatorname{PFP}\left(\mathrm{C}_{12} \mathrm{E}_{5}\right)_{x}$ appeared visually cloudy for $x<1$ and perfectly transparent (or slightly bluish due to the fluorescence) for $x \geq 1$.

Phase Boundaries. Phase behavior was probed by using PL, surface tension $(\sigma)$, static contact angle, and $(\pi-A)$ isotherm measurements. Figure 2 plots essential examples of the PL spectra of $\mathrm{D}_{2} \mathrm{O}-\mathrm{PBS}-\mathrm{PFP}\left(\mathrm{C}_{12} \mathrm{E}_{5}\right)_{x}$ as a function of molar ratio $x$. Figure 3 plots in turn the position of the $0-0$ maximum as a function of $x$. A progressive blue shift of the whole PL spectrum, with the spectral maximum shifting from 430 to 419 $\mathrm{nm}$, occurs on surfactant addition.

Figure 4 plots surface tension and static contact angle on hydrophobic surfaces. When PBS-PFP is added to $\mathrm{D}_{2} \mathrm{O}, \sigma$ drops some $5 \mathrm{mN} / \mathrm{m}$. Adding surfactant causes $\sigma$ to drop further until it approaches the level of the binary system at $x \sim 4$. On average,

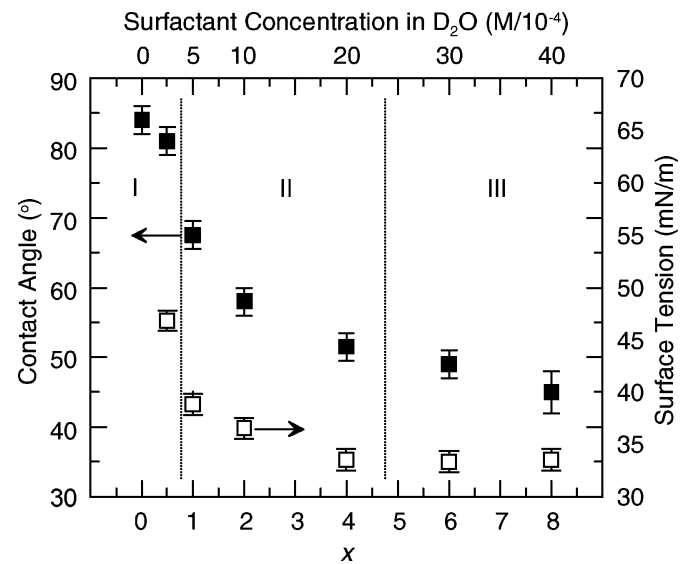

Figure 4. Contact angle (solid squares) and surface tension (open squares) of $\mathrm{D}_{2} \mathrm{O}-\mathrm{PBS}-\mathrm{PFP}\left(\mathrm{C}_{12} \mathrm{E}_{5}\right)_{x}$ as a function of molar ratio $x$. The dotted lines distinguish tentative phase regimes I-III. $T=20^{\circ} \mathrm{C}$.

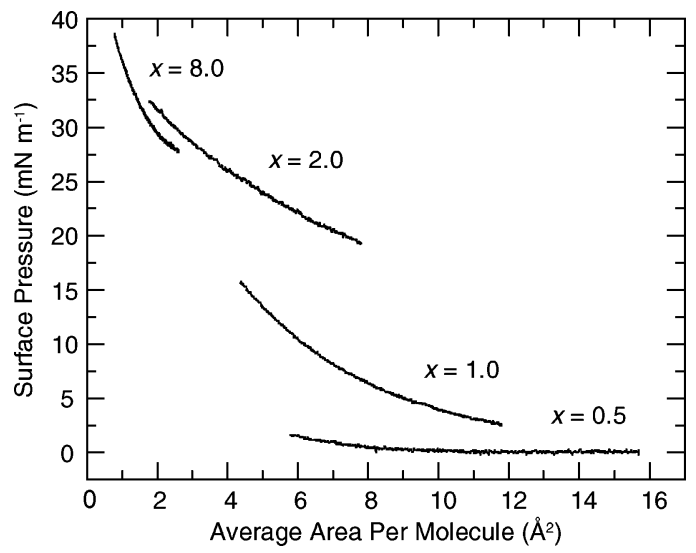

Figure 5. Characteristic $(\pi-A)$ isotherms of $\mathrm{PBS}-\mathrm{PFP}\left(\mathrm{C}_{12} \mathrm{E}_{5}\right)_{x}$ solutions for $x=0.5,1,2$, and 8 measured with a compression speed of $9.4 \times 10^{-5}-4.2 \times 10^{-4} \mathrm{~nm}^{2} /(\mathrm{s} \cdot$ molecule $)$ at a temperature of $20 \pm$ $1{ }^{\circ} \mathrm{C}$.

the surface tension of the ternary system for $x>4$ is somewhat higher than that of equally concentrated binary ones. Static contact angle behaves much like surface tension approaching that of pure $\mathrm{D}_{2} \mathrm{O}$ for small $x$ and that of binary solution for $x>$ 4 yet remaining higher than those of equally concentrated binary systems. The results obtained are compiled in Table 1.

Figure 5 plots typical surface pressure - area $(\pi-A)$ isotherms of PBS-PFP $\left(\mathrm{C}_{12} \mathrm{E}_{5}\right)_{x}$ on a pure water subphase. For $x=0.5$, $1.0,2.0$, and $8.0,0.22 \mathrm{~mL}$ of solution with concentrations of $0.46,0.56,0.77$, and $1.99 \mathrm{mg} / \mathrm{mL}$, respectively, was spread. Three phenomenological regimes can be recognized corresponding to those shown in Figures 3 and 4. When precipitated macroscopic particles of PBS-PFP in water are seen for $x=$ 0.5 , the surface pressure approaches zero. The transparent mixture with higher surfactant fractions $(x=1)$ results in an expanded isotherm, with a distinct upturn with decreasing surface area. This indicates the formation of a floating layer at the water-air interface. The surface pressure increases when $x$ is increased from 1 to 2 but essentially saturates for $x>2$.

Inspecting Figures 3-5, three different regimes of dissolution of PBS-PFP in the $\mathrm{C}_{12} \mathrm{E}_{5}$ /water mixture are observed. At lower concentrations of $\mathrm{C}_{12} \mathrm{E}_{5}(x<1)$ the rapidly decreasing surface tension and contact angle and approximately solid state PL indicate that interaction between polymer and surfactant is quite low and that surfactant molecules are predominantly free in the solution. We denote this as Regime I.

At intermediate concentration of $\mathrm{C}_{12} \mathrm{E}_{5} x=1-4$ the emerging blue shift in PL points to the gradual dissolution of the polymer, 
TABLE 1: Materials Parameters of the Studied Samples in $\mathrm{D}_{2} \mathrm{O}$ at $20{ }^{\circ} \mathrm{C}$

\begin{tabular}{|c|c|c|c|c|c|c|c|}
\hline material & $\begin{array}{c}\text { monomer } \\
\text { concn } c_{\mathrm{m}}(\mathrm{M})\end{array}$ & $\begin{array}{c}\text { surfactant } \\
\text { concn } c_{\mathrm{s}}(\mathrm{M})\end{array}$ & $\begin{array}{c}\text { overall } \\
\text { concn }(\mathrm{mg} / \mathrm{mL})\end{array}$ & $\begin{array}{c}\text { visual } \\
\text { appearance }\end{array}$ & $\begin{array}{c}\text { first PL } \\
\max (\mathrm{nm})\end{array}$ & $\begin{array}{c}\text { surface } \\
\text { tension } \sigma \\
(\mathrm{mN} / \mathrm{m})\end{array}$ & $\begin{array}{c}\text { contact } \\
\text { angle (deg) }\end{array}$ \\
\hline $\mathrm{C}_{12} \mathrm{E}_{5}$ & 0 & $2.5 \times 10^{-4}$ & $0.10 \pm 0.02$ & transparent & $\mathrm{n} / \mathrm{a}$ & $32.5 \pm 1.0$ & $85.5 \pm 1.0$ \\
\hline $\mathrm{C}_{12} \mathrm{E}_{5}$ & 0 & $10 \times 10^{-4}$ & $0.41 \pm 0.02$ & transparent & $\mathrm{n} / \mathrm{a}$ & $30.6 \pm 1.0$ & $40.0 \pm 2.0$ \\
\hline $\mathrm{C}_{12} \mathrm{E}_{5}$ & 0 & $30 \times 10^{-4}$ & $1.22 \pm 0.02$ & transparent & $\mathrm{n} / \mathrm{a}$ & $31.0 \pm 1.0$ & $38.5 \pm 2.0$ \\
\hline $\mathrm{C}_{12} \mathrm{E}_{5}$ & 0 & $100 \times 10^{-4}$ & $4.07 \pm 0.02$ & transparent & $\mathrm{n} / \mathrm{a}$ & $31.1 \pm 1.0$ & $33.5 \pm 2.0$ \\
\hline PBS-PFP & $5 \times 10^{-4}$ & 0 & $0.36 \pm 0.02$ & precipitated particles & 430 & $\mathrm{n} / \mathrm{a}$ & $84.0 \pm 0.5$ \\
\hline PBS-PFP & $2.5 \times 10^{-4}$ & 0 & $0.18 \pm 0.02$ & precipitated particles & & $\mathrm{n} / \mathrm{a}$ & \\
\hline PBS-PFP $\left(\mathrm{C}_{12} \mathrm{E}_{5}\right)_{0.5}$ & $5 \times 10^{-4}$ & $2.5 \times 10^{-4}$ & $0.46 \pm 0.02$ & cloudy but no particles & 430 & $46.8 \pm 1.0$ & $81.0 \pm 0.5$ \\
\hline $\mathrm{PBS}-\mathrm{PFP}\left(\mathrm{C}_{12} \mathrm{E}_{5}\right)_{1.0}$ & $5 \times 10^{-4}$ & $5 \times 10^{-4}$ & $0.56 \pm 0.02$ & transparent & 430 & $38.8 \pm 1.0$ & $67.5 \pm 0.5$ \\
\hline $\mathrm{PBS}-\mathrm{PFP}\left(\mathrm{C}_{12} \mathrm{E}_{5}\right)_{2.0}$ & $5 \times 10^{-4}$ & $10 \times 10^{-4}$ & $0.77 \pm 0.02$ & transparent & 426 & $36.5 \pm 1.0$ & $58.0 \pm 2.0$ \\
\hline PBS-PFP $\left(\mathrm{C}_{12} \mathrm{E}_{5}\right)_{4.0}$ & $5 \times 10^{-4}$ & $20 \times 10^{-4}$ & $1.17 \pm 0.02$ & transparent & 424 & $33.5 \pm 1.0$ & $51.5 \pm 2.0$ \\
\hline PBS-PFP $\left(\mathrm{C}_{12} \mathrm{E}_{5}\right)_{6.0}$ & $5 \times 10^{-4}$ & $30 \times 10^{-4}$ & $1.58 \pm 0.02$ & transparent & 419 & $33.3 \pm 1.0$ & $49.0 \pm 2.0$ \\
\hline $\mathrm{PBS}-\mathrm{PFP}\left(\mathrm{C}_{12} \mathrm{E}_{5}\right)_{8.0}$ & $5 \times 10^{-4}$ & $40 \times 10^{-4}$ & $1.99 \pm 0.02$ & transparent & 419 & $33.5 \pm 1.0$ & $45.0 \pm 2.0$ \\
\hline $\mathrm{PBS}-\mathrm{PFP}\left(\mathrm{C}_{12} \mathrm{E}_{5}\right)_{10.0}$ & $5 \times 10^{-4}$ & $50 \times 10^{-4}$ & $2.39 \pm 0.02$ & transparent & & $31.1 \pm 1.0$ & $42.0 \pm 2.0$ \\
\hline
\end{tabular}

while the moderately decreasing surface tension and contact angle shows the saturation of the free surfactant concentration, i.e., that there is a strong polymer-surfactant interaction. This could be somewhat analogous to the critical aggregate concentration (CAC) of colloid science. This is Regime II. In this regime, surfactant molecules are suggested to be partly located close to the polymer and partly at the interface. In other words, the interaction between polymer and surfactant may not be strong enough to catch all surfactant molecules and we may call this noncooperative binding of $\mathrm{C}_{12} \mathrm{E}_{5}$.

Finally at high $x>4$ we observe constant values of all parameters, which indicates that the fraction of free $\mathrm{C}_{12} \mathrm{E}_{5}$ is constant and that the surplus $\mathrm{C}_{12} \mathrm{E}_{5}$ is bound at the aggregates (polymer-surfactant or pure surfactant). This means that we observe cooperative binding of $\mathrm{C}_{12} \mathrm{E}_{5}$. We denote this as Regime III. We note in the end that no macrophase separation occurred after 6 months so the transparent solutions seem to represent an equilibrium state.

Particle Structure in Aqueous Solution. The nanoscale structure of the particles in aqueous solution was studied with SANS. To obtain information on the conformation of the pure PBS-PFP, we dissolved it first in deuterated DMSO at 0.1 wt $\%$, which resulted in a transparent solution. The SANS curve of this solution is, however, not distinguishable from the background. The small molecular weight of the polymer $(\sim 10$ units) and the incorporation of the side chains into the solvent prevented measurements of its structure as could be done for a high molecular weight $\mathrm{PF}^{49,50}$ dissolved in $d$-toluene.

Cloudy Mixtures of $\mathrm{D}_{2} \mathrm{O}-\mathrm{PBS}-\mathrm{PFP}\left(\mathrm{C}_{12} E_{5}\right)_{x}$ at the Low Surfactant Fraction Limit $x \rightarrow 0$. As ternary $\mathrm{D}_{2} \mathrm{O}-\mathrm{PBS}-\mathrm{PFP}-$ $\left(\mathrm{C}_{12} \mathrm{E}_{5}\right)_{x}$ for $x \leq 0.5$ is visually cloudy, the SANS method will detect only that fraction of the colloidal objects which fall into

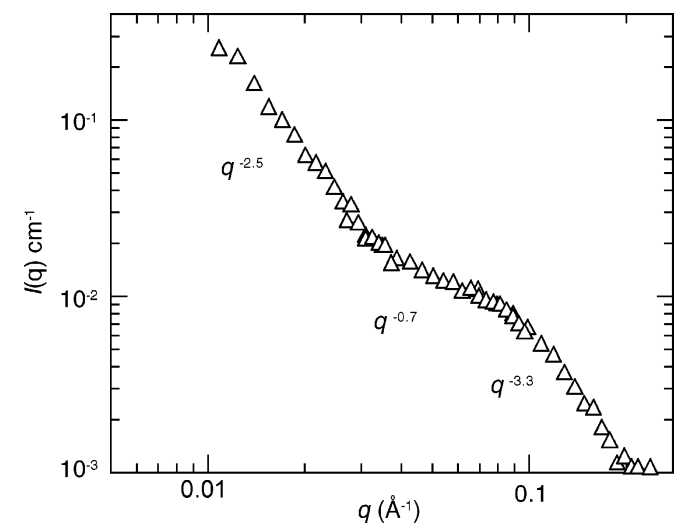

Figure 6. SANS data of $D_{2} \mathrm{O}-\mathrm{PBS}-\mathrm{PFP}\left(\mathrm{C}_{12} \mathrm{E}_{5}\right)_{0.5}$ for a monomer concentration of $5 \times 10^{-4} \mathrm{M} . T=20^{\circ} \mathrm{C}$. its observation window $\left(<2 \pi / q_{\min } \approx 1000 \AA\right.$ ). Figure 6 plots the scattering curves for the ternary system at low surfactant concentration, $x=0.5$. The power law scattering at the lowest $q$-range indicates the presence of large aggregates. For $q>0.03$ $\AA^{-1}$, the scattering curve resembles those seen in Regime II (see later, Figure 7). This indicates the appearance of aggregates with characteristic sizes of the order of $100 \AA$. At the highest $q$, the intensity decreases as $\sim q^{-3.3}$. Altogether, we see that in Regime I the polymer crystals start to dissolve with the assistance of the surfactant.

Visually Transparent Solutions of $D_{2} O-P B S-P F P\left(C_{12} E_{5}\right)_{x}$ at Intermediate Surfactant Fraction, $x=1-4$. Figure 7 plots SANS data of $\mathrm{D}_{2} \mathrm{O}-\mathrm{PBS}-\mathrm{PFP}\left(\mathrm{C}_{12} \mathrm{E}_{5}\right)_{2.0}$ and $\mathrm{D}_{2} \mathrm{O}-\mathrm{C}_{12} \mathrm{E}_{5}$ of the corresponding surfactant concentration as well as fits obtained from the IFT. The scattering intensity follows a power law $\sim q^{-1}$ over wide $q$-range. Figure 8 plots the cross-sectional pair correlation functions obtained from the IFT at $q>0.02 \AA$ -1 . Table 2 summarizes the cross-sectional parameters. The upper limits for the cross-sectional pair correlation function are found to be $34 \AA$ for the aggregates in the ternary system and $44 \AA$ in the binary system. The radius of the cross section obtained by circular approximation is smaller for PBS-PFP$\left(\mathrm{C}_{12} \mathrm{E}_{5}\right)_{x}$ aggregates with $x=1$ and 2 than for $\mathrm{C}_{12} \mathrm{E}_{5}$ micelles at a similar concentration. The values of mass per unit length obtained are in agreement with the values of radii and show that $\mathrm{PBS}-\mathrm{PFP}\left(\mathrm{C}_{12} \mathrm{E}_{5}\right)_{x}$ aggregates with $x=1$ and 2 consist of

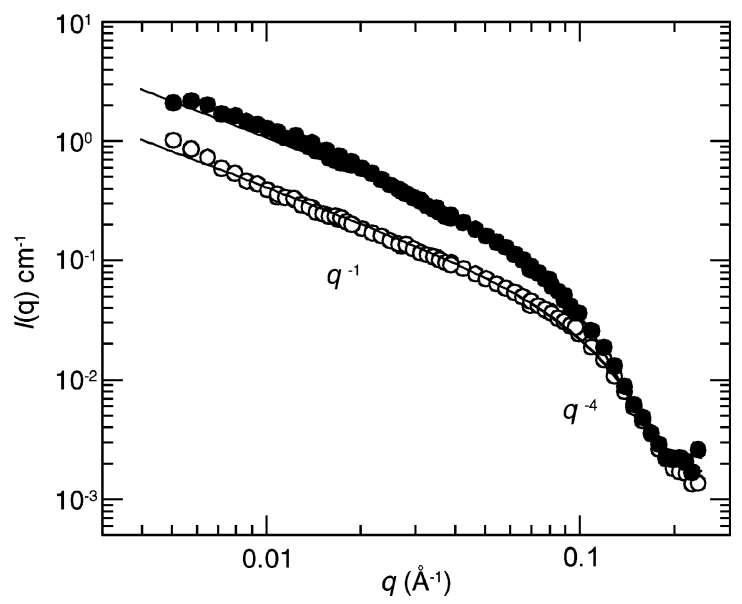

Figure 7. SANS data of $\mathrm{D}_{2} \mathrm{O}-\mathrm{PBS}-\mathrm{PFP}\left(\mathrm{C}_{12} \mathrm{E}_{5}\right)_{2.0}$ with a monomer concentration of $5 \times 10^{-4} \mathrm{M}$ (open symbols) and $\mathrm{D}_{2} \mathrm{O}-\mathrm{C}_{12} \mathrm{E}_{5}$ with a concentration of $10 \times 10^{-4} \mathrm{M}$ (solid symbols, intensities were multiplied by 2 for clarity), which corresponds to the surfactant concentration of the case $x=2$ as well as the corresponding fits obtained by IFT. $T=$ $20{ }^{\circ} \mathrm{C}$. 
TABLE 2: Cross Sectional Parameters of Rodlike Aggregates of PBS-PFP( $\left(C_{12} E_{5}\right)_{x}$ and Micelles of $C_{12} E_{5}$ Obtained by Model Independent Analysis ${ }^{a}$

\begin{tabular}{|c|c|c|c|c|c|c|c|}
\hline material & $\begin{array}{c}\text { monomer } \\
\text { concn } c_{\mathrm{m}}(\mathrm{M})\end{array}$ & $\begin{array}{c}\text { surfactant } \\
\text { concn } c_{\mathrm{S}}(\mathrm{M})\end{array}$ & $\begin{array}{l}R_{\mathrm{CS} ; \mathrm{g}} \\
(\AA)\end{array}$ & $\begin{array}{c}R \\
(\AA)\end{array}$ & $\begin{array}{c}M_{\mathrm{L}}, 10^{-13} \\
\quad(\mathrm{~g} / \mathrm{cm})\end{array}$ & $\begin{array}{c}\text { no. of } \\
\text { monomers/nm }\end{array}$ & $\begin{array}{c}\text { no. of } \mathrm{C}_{12} \mathrm{E}_{5} \\
\text { molecules/nm }\end{array}$ \\
\hline $\mathrm{C}_{12} \mathrm{E}_{5}$ & 0 & $2.5 \times 10^{-4}$ & $14.5 \pm 0.2$ & 20.5 & 0.99 & 0 & 15 \\
\hline $\mathrm{C}_{12} \mathrm{E}_{5}$ & 0 & $10 \times 10^{-4}$ & $15.2 \pm 0.3$ & 21.5 & 1.01 & 0 & 15 \\
\hline $\mathrm{C}_{12} \mathrm{E}_{5}$ & 0 & $30 \times 10^{-4}$ & $15.6 \pm 0.3$ & 22.1 & 1.02 & 0 & 15 \\
\hline $\mathrm{PBS}-\mathrm{PFP}\left(\mathrm{C}_{12} \mathrm{E}_{5}\right)_{1.0}$ & $5 \times 10^{-4}$ & $5 \times 10^{-4}$ & $10.2 \pm 0.3$ & 14.1 & 0.389 & 2 & 2 \\
\hline $\mathrm{PBS}-\mathrm{PFP}\left(\mathrm{C}_{12} \mathrm{E}_{5}\right)_{2.0}$ & $5 \times 10^{-4}$ & $10 \times 10^{-4}$ & $11.6 \pm 0.2$ & 16.4 & 0.513 & 2 & 4 \\
\hline
\end{tabular}

${ }^{a} R$ is the radius of the cross section in homogeneous and circular approximation of the cross section. $M_{\mathrm{L}}$ is the average mass of aggregates per $1 \mathrm{~cm}$, also the present number of monomer of PBS- $\mathrm{PFP}\left(\mathrm{C}_{12} \mathrm{E}_{5}\right)$ per $1 \mathrm{~nm}$ and the number of $\mathrm{C}_{12} \mathrm{E}_{5}$ molecules per $1 \mathrm{~nm}$ in the case of aggregates and pure micelles.

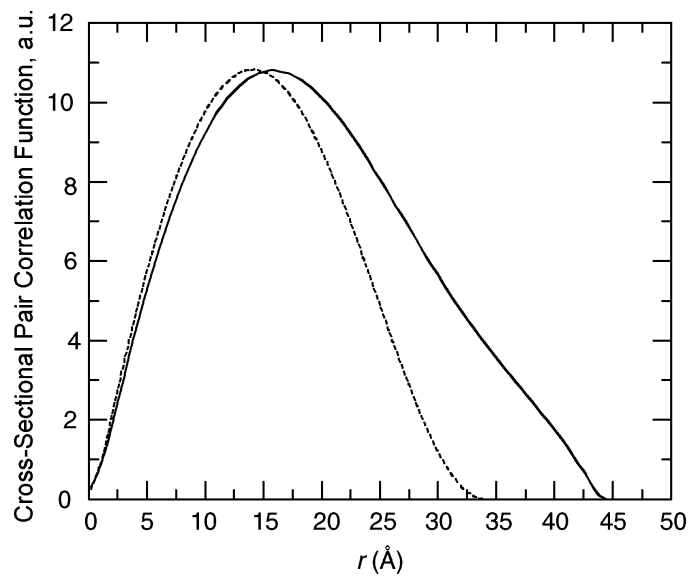

Figure 8. $\tilde{p}_{\mathrm{CS}}(r)$ obtained by IFT from the scattering curves: solid line for $\mathrm{D}_{2} \mathrm{O}-\mathrm{C}_{12} \mathrm{E}_{5}$ with a concentration of $10 \times 10^{-4} \mathrm{M}$ and dashed line for $\mathrm{D}_{2} \mathrm{O}-\mathrm{PBS}-\mathrm{PFP}\left(\mathrm{C}_{12} \mathrm{E}_{5}\right)_{2.0}$ with a monomer concentration of 5 $\times 10^{-4}$ M. $T=20^{\circ} \mathrm{C}$.

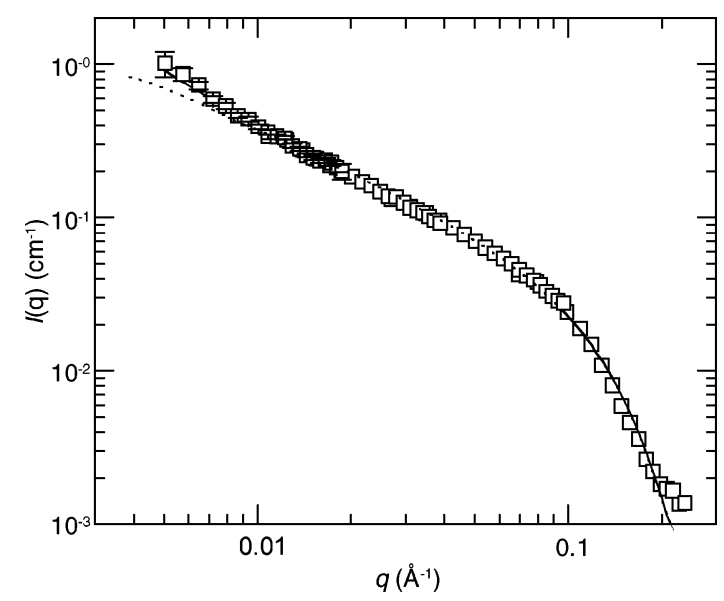

Figure 9. SANS data of $\operatorname{PBS}-\operatorname{PFP}\left(\mathrm{C}_{12} \mathrm{E}_{5}\right)_{2.0}$ with a monomer concentration of $5 \times 10^{-4} \mathrm{M}$ and fit by flexible (solid line) and stiff cylinder models (dashed line). $T=20^{\circ} \mathrm{C}$.

2 repeat units and 2-4 surfactant molecules per nanometer. In contrast, $\mathrm{C}_{12} \mathrm{E}_{5}$ micelles consist of $\sim 15$ molecules per nanometer.

Figure 9 plots the data of $\mathrm{D}_{2} \mathrm{O}-\mathrm{PBS}-\mathrm{PFP}\left(\mathrm{C}_{12} \mathrm{E}_{5}\right)_{2.0}$ and corresponding fits to the models of a stiff and flexible cylinder. The cross section is nearly circular. The flexible model results in a contour length of $900 \pm 100 \AA$, a persistence length of $300 \pm 30 \AA$, and a radius $R=15.2 \pm 0.5 \AA$ while the stiff cylinder model yields a length of $880 \pm 80 \AA$ and a radius $R=$ $15.4 \pm 0.5 \AA$ for $\mathrm{D}_{2} \mathrm{O}-\mathrm{PBS}-\operatorname{PFP}\left(\mathrm{C}_{12} \mathrm{E}_{5}\right)_{2.0}$. The application of the flexible model to SANS data of equally dense $\mathrm{D}_{2} \mathrm{O}-$ $\mathrm{C}_{12} \mathrm{E}_{5}\left(10 \times 10^{-4} \mathrm{M}\right)$ solution yields the values of $750 \pm 80$ and $120 \pm 10 \AA$, respectively, for the contour and persistence lengths. The cross section is not circular. Fitting it with the

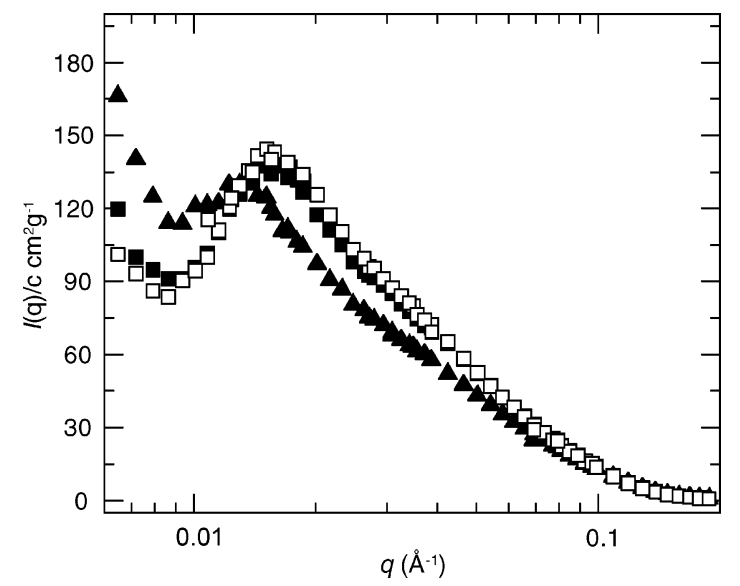

Figure 10. SANS data of $\mathrm{D}_{2} \mathrm{O}-\mathrm{PBS}-\mathrm{PFP}\left(\mathrm{C}_{12} \mathrm{E}_{5}\right)_{x}$ for a monomer concentration of $5 \times 10^{-4} \mathrm{M}$ with $x=4$ (solid triangles), 6 (solid squares), and 8 (open squares) normalized to a total concentration of PBS-PFP and $\mathrm{C}_{12} \mathrm{E}_{5} . T=20^{\circ} \mathrm{C}$.

ellipsoid model results in values of semi-axes $A=26.0 \pm 0.5$ $\AA$ and $B=16.0 \pm 0.5 \AA$.

Overall, the solutions are transparent and SANS data suggest the formation of elongated aggregates which are not $\mathrm{C}_{12} \mathrm{E}_{5}$ micelles. The aggregates are thinner (with nearly circular cross section) and have lower mass per unit length than corresponding pure micelles. Two quite different models yield similar characteristics of the aggregates' size. The stiff cylinder model fits well apart from lowest $q$ (cf. Figure 9) while the flexible cylinder model fits well over the whole $q$-range. However, the ratio between total length and persistence length is $<3$, which suggests that the aggregates are stiff rather than flexible.

Visually Transparent Solutions of $D_{2} O-P B S-P F P\left(C_{12} E_{5}\right)_{x}$ at the High Surfactant Fraction, $x>4$. Figure 10 plots SANS data of $\mathrm{D}_{2} \mathrm{O}-\mathrm{PBS}-\mathrm{PFP}\left(\mathrm{C}_{12} \mathrm{E}_{5}\right)_{x}$ for $x>2$. The scattering intensities are normalized to the total concentration of PBSPFP and $\mathrm{C}_{12} \mathrm{E}_{5}$. A clear transition is seen when the molar ratio is increased to $x=4$. A distinct interference maximum appears at $0.015-0.02 \AA^{-1}$ (the scattering angle increasing with $x$ ) and potentially a very broad maximum at $0.025-0.035 \AA^{-1}$. The position of this maximum is the same for $x=6$ and 8 , which implies that the intermicellar distance does not change much with increasing $x$. The values of normalized intensities are higher for $x=8$ than for $x=6$, which implies the growth of aggregates with increasing $x$. The determination of the number of PBSPFP repeat units from the position of the interference maximum (eq 9) yields $\sim 20$ PBS - PFP repeat units and $\sim 160$ surfactant molecules per one aggregate at $x=8$. This means that each aggregate contains two polymers on average. The characteristic dimension of the aggregates is of the order of $40 \AA$.

Figure 11 plots the SANS data of $\mathrm{D}_{2} \mathrm{O}-\mathrm{PBS}-\mathrm{PFP}\left(\mathrm{C}_{12} \mathrm{E}_{5}\right)_{8.0}$ on dilution by $\mathrm{D}_{2} \mathrm{O}$. Figure 12 plots the position of the maximum as a function of concentration for $x=8$ and 10. We observe 


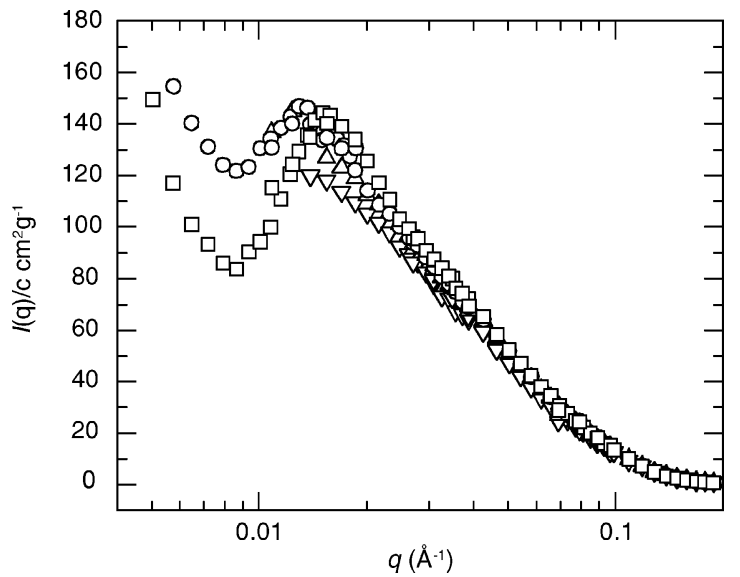

Figure 11. SANS data of $\mathrm{D}_{2} \mathrm{O}-\mathrm{PBS}-\mathrm{PFP}\left(\mathrm{C}_{12} \mathrm{E}_{5}\right)_{x}$ for $x=8$ with a PBS-PFP concentration of $5 \times 10^{-4}$ (squares), $2.5 \times 10^{-4}$ (spheres), $1.25 \times 10^{-4}$ (upper triangles), and $0.625 \times 10^{-4} \mathrm{M}$ (lower triangles). $T=20^{\circ} \mathrm{C}$.

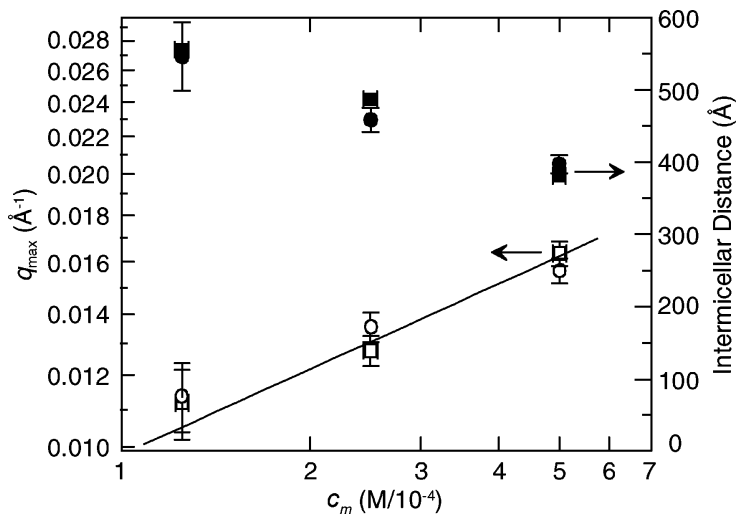

Figure 12. The $q_{\max }$ (open symbols) and intermicellar distance (solid symbols) vs monomer concentration $c_{\mathrm{m}}$ corresponding to $x=8$ (squares) and 10 (spheres). The solid line is a linear fit of $q_{\max }$ for $x=8 . T=20$ ${ }^{\circ} \mathrm{C}$.

TABLE 3: The Intermicellar Distance and Surface Tension of $\mathrm{D}_{2} \mathrm{O}-\mathrm{PBS}-\mathrm{PFP}\left(\mathrm{C}_{12} \mathrm{E}_{5}\right)_{x}$ as a Function of Molar Ratio $x$ and Overall Concentration

\begin{tabular}{clccc}
\hline $\begin{array}{c}\text { molar } \\
\text { ratio } x\end{array}$ & $\begin{array}{c}\text { monomer } \\
\text { concn } c_{\mathrm{m}} \\
(\mathrm{M})\end{array}$ & $\begin{array}{c}\text { overall } \\
\text { concn } \\
(\mathrm{mg} / \mathrm{mL})\end{array}$ & $\begin{array}{c}\text { surface } \\
\text { tension } \sigma \\
(\mathrm{mN} / \mathrm{m})\end{array}$ & $\begin{array}{c}\text { interm. } \\
\text { distance } l \\
(\mathrm{~nm})\end{array}$ \\
\hline 4.0 & $5 \times 10^{-4}$ & $1.17 \pm 0.02$ & $33.5 \pm 1.0$ & $48 \pm 1$ \\
6.0 & $5 \times 10^{-4}$ & $1.58 \pm 0.02$ & $33.3 \pm 1.0$ & $42 \pm 1$ \\
8.0 & $5 \times 10^{-4}$ & $1.99 \pm 0.02$ & $33.5 \pm 1.0$ & $38 \pm 1$ \\
8.0 & $2.5 \times 10^{-4}$ & $0.99 \pm 0.02$ & $33.4 \pm 1.0$ & $49 \pm 1$ \\
8.0 & $1.25 \times 10^{-4}$ & $0.50 \pm 0.02$ & $32.7 \pm 1.0$ & $55 \pm 2$ \\
8.0 & $0.625 \times 10^{-4}$ & $0.25 \pm 0.02$ & $34.2 \pm 1.0$ & $\mathrm{n} / \mathrm{a}$ \\
8.0 & $0.3125 \times 10^{-4}$ & $0.12 \pm 0.02$ & $36.1 \pm 1.0$ & $\mathrm{n} / \mathrm{a}$ \\
10.0 & $5 \times 10^{-4}$ & $2.39 \pm 0.02$ & $31.1 \pm 1.0$ & $40 \pm 1$ \\
10.0 & $2.5 \times 10^{-4}$ & $1.96 \pm 0.02$ & $32.2 \pm 1.0$ & $46 \pm 1$ \\
10.0 & $1.25 \times 10^{-4}$ & $0.60 \pm 0.02$ & $32.3 \pm 1.0$ & $56 \pm 2$ \\
10.0 & $0.625 \times 10^{-4}$ & $0.30 \pm 0.02$ & $32.9 \pm 1.0$ & $\mathrm{n} / \mathrm{a}$
\end{tabular}

scaling $q_{\max } \sim c^{0.31 \pm 0.05} \approx c^{1 / 3}$, which suggests that the distance between micelles increases in a way of $3 \mathrm{D}$ packing. ${ }^{51,52}$ The interference maximum, which depends mainly on concentration of polymer according to $3 \mathrm{D}$ packing, implies that the concentration of $\mathrm{C}_{12} \mathrm{E}_{5}$ aggregates is determined by the number of active sites in polymer molecules. The intermicellar distance (long period) and surface tension as a function of molar ratio and concentration are displayed in Table 3 . Surface tension stays constant on dilution, which further enforces the idea of cooperative binding.

Floating Aggregate Layer at the Air-Water Interface. The floating layers of $\mathrm{PBS}-\operatorname{PFP}\left(\mathrm{C}_{12} \mathrm{E}_{5}\right)_{x}$ at the air-water interface

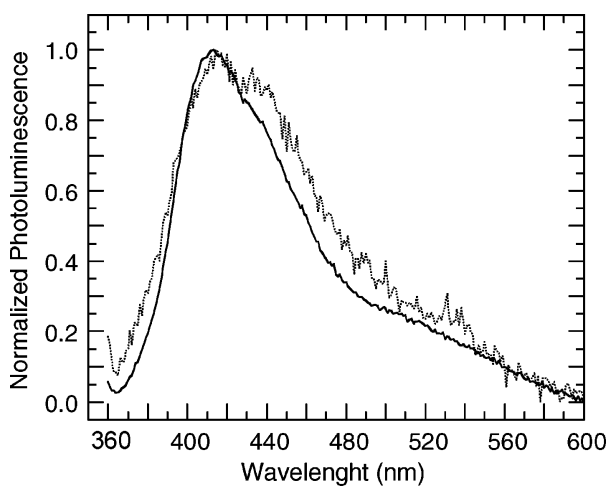

Figure 13. PL spectra of nominal PBS $-\mathrm{PFP}\left(\mathrm{C}_{12} \mathrm{E}_{5}\right)_{2.0}$ monolayers on hydrophilic (solid line) and hydrophobic glass (dashed line).

were studied by using Langmuir-Blodgett dipping with hydrophilic and hydrophobic glass substrates. Unsurprisingly, the dipping was unsuccessful for $x=0.5$. When higher surfactant fractions were used and surface pressure kept constant, we observed a smooth kink in the slope of the interface area at the beginning of the dipping with hydrophilic substrate suggesting material transfer from the subphase. This effect was not seen with hydrophobic glass. As the highest amount of polymer was anticipated to be transferred by keeping the polymer fraction and surface pressure simultaneously high, we considered high surface pressure at the low surfactant fraction limit, i.e., $x=2$. As the surface tension of PBS- PFP $\left(\mathrm{C}_{12} \mathrm{E}_{5}\right)_{2.0}$ does not approach that of aqueous surfactant (cf. Figure 4), no substantial surfactant surplus was assumed. Figure 13 plots the PL spectra of nominal PBS- $\operatorname{PFP}\left(\mathrm{C}_{12} \mathrm{E}_{5}\right)_{2.0}$ monolayers on hydrophilic and hydrophobic glass showing the characteristic PL of polyfluorene.

\section{Discussion}

Solution Formation. In our work, the first "definition" of dissolution is the visual transparency and under the studied concentration regime this occurs for $\mathrm{D}_{2} \mathrm{O}-\mathrm{PBS}-\mathrm{PFP}\left(\mathrm{C}_{12} \mathrm{E}_{5}\right)_{x}$ at $x \geq 1$. Formation of a transparent ternary system supports the previous assumption of the polymer particles broken by $\mathrm{C}_{12} \mathrm{E}_{5}$ surfactant. ${ }^{14}$ Nevertheless, bare visual consideration does not indicate that PBS-PFP would be dissolved down to the molecular level. It simply means that no gross macroscopic particles are seen.

Phase Boundaries. The binary water $-\mathrm{C}_{12} \mathrm{E}_{5}$ system is an appropriate starting point for our discussion. It reveals a CMC of around $5 \times 10^{-5} \mathrm{M}^{22}$ Near room temperature it shows an isotropic liquid $\mathrm{L}_{1}$ phase when the $\mathrm{C}_{12} \mathrm{E}_{5}$ fraction is below $\sim 35$ wt $\%,{ }^{32}$ which corresponds to a $\mathrm{C}_{12} \mathrm{E}_{5}$ concentration of $\sim 9 \times$ $10^{-1} \mathrm{M}$. The normal hexagonal $\mathrm{H}_{1}$ phase is seen for higher surfactant concentrations. Transition from an $\mathrm{L}_{1}$ to an $\mathrm{L}_{1}^{\prime}+$ $\mathrm{L}_{1}{ }^{\prime \prime}$ phase occurs at $T=35-50{ }^{\circ} \mathrm{C}$, increasing with $\mathrm{C}_{12} \mathrm{E}_{5}$ fraction. ${ }^{32}$ The present study was performed at $20{ }^{\circ} \mathrm{C}$ with the surfactant concentration between $2.5 \times 10^{-4}$ and $75 \times 10^{-4}$ M. Therefore, the studied "base" binary mixture at $20^{\circ} \mathrm{C}$ would correspond to the $\mathrm{L}_{1}$ phase above the CMC.

A progressive blue shift of the whole PL spectrum, with the spectral maximum shifting from 430 to $419 \mathrm{~nm}$, occurs on suggestive polymer dissolution (Figure 2). The "solution PL" indicates that polymer chains are fully separated from each other but here its form does not depend on the nature of the surrounding media. This result differs slightly from the previous study that suggested a shift down to $412 \mathrm{~nm},{ }^{14}$ a fact that presumably stems from the lower overall concentration. The PL characteristics of water-PBS-PFP $\left(\mathrm{C}_{12} \mathrm{E}_{5}\right)^{14}$ can also be found elsewhere. The overall situation illustrated in Figure 3 
gives us tentatively three phenomenological phase regimes: two possible plateaus for $x<1$ (Regime I) and $x>4$ (Regime III) where, respectively, the PL spectrum approaches that of the solid state and solution PL of PF, as well as the intermediate region for $x=1-4$ (Regime II).

The idea of three phase regimes is supported by surface tension and static contact angle. Figure 4 illustrates regimes where $\sigma$ approaches the values of pure $\mathrm{D}_{2} \mathrm{O}$ and pure aqueous $\mathrm{C}_{12} \mathrm{E}_{5}$. In phase Regime II the values of $\sigma$ are low but still higher than those in Regime III in which they are still slightly higher than those in binary systems. This suggests that the free surfactant molecules are present in Regime II at a concentration smaller than the CMC. These observations are in accordance with the changes in contact angle (Figure 4). As both surface tension and contact angle of aqueous PBS $-\mathrm{PFP}\left(\mathrm{C}_{12} \mathrm{E}_{5}\right)_{x}$ are consistently slightly larger than those of correspondingly concentrated aqueous $\mathrm{C}_{12} \mathrm{E}_{5}$, we expect that PBS-PFP binds part of $\mathrm{C}_{12} \mathrm{E}_{5}$. The surface tension ${ }^{26}$ and contact angle ${ }^{53}$ of $\mathrm{C}_{12} \mathrm{E}_{5}$ and $\mathrm{C}_{12} \mathrm{E}_{5} /$ oil systems have been reported elsewhere.

Finally, three phenomenological regimes may be recognized in the $(\pi-A)$ isotherms as well (Figure 5). When precipitated macroscopic particles of PBS-PFP in water are seen for $x=$ 0.5 , the surface pressure approaches zero indicating negligible film formation at the air-water interface. This supports the above-mentioned assumption that PBS-PFP is at or below the solubilization limit and binds the majority of surfactants for $x$ $=0.5$. The higher surfactant fraction $(x=1)$ leads to a floating layer at the water-air interface. The surface pressure increases rapidly with $\mathrm{C}_{12} \mathrm{E}_{5}$ fraction but saturates for $x \geq 2$, separating Regimes II and III. We observed some fluctuations when the measurements were repeated, which is potentially due to the instability of the layer. However, the gross deviation between the three regimes was reproduced.

In this framework, the solution structure of Regimes I-III was then studied by using SANS. We have shown in section 4 that the suggested regimes correspond to the SANS data, where the distinction between Regimes II and III is, however, observed between $x=2$ and 4 rather than between $x=1$ and 2 . Below we discuss SANS data of $\mathrm{D}_{2} \mathrm{O}-\mathrm{PBS}-\mathrm{PFP}\left(\mathrm{C}_{12} \mathrm{E}_{5}\right)_{x}$ for $x=$ $1-10$, show comparison to $\mathrm{D}_{2} \mathrm{O}-\mathrm{C}_{12} \mathrm{E}_{5}$ in similar conditions and provide an interpretation for the different regimes.

Particle Structure in Solution. Regime I, $x \leq 0.5$ : Partial Solubilization. PBS-PFP is not water soluble but forms a cloudy mixture with a typical solid-state PL spectrum (cf. Figure 2). The existence of nondissolved particles prevents us from giving a reliable quantitative analysis. However, inspecting SANS data plotted in Figure 6, the following conclusions can be drawn. The slope -2.5 at smallest $q$ can imply the presence of large, polydisperse or mass fractal objects (>1000 ̊). Assuming mass fractals, their fractal dimension $D_{\mathrm{m}}$ would be equal to the value of the slope. ${ }^{54}$ The region with slope -0.7 appears to be crossover toward the scattering pattern from the smaller objects, which display a slope of -3.3 at highest $q$. This would correspond to a surface-fractal-like surface of these particles, ${ }^{54}$ which are presumably aggregates formed by the dissolved polymers and surfactant molecules. Altogether, we propose that we observe large nondissolved polymer particles, and "mixed" surfactant-polymer aggregates, similar to what exist in Regime II (see below).

Regime II, $1 \leq x \leq 4$ : Dissolved Aggregates. This regime is important as a low fraction of surfactant and potential solubilization are simultaneously achieved. We draw attention to the following features seen in Figures 7 and 8 following the classic texts. ${ }^{54,55}$ First, in contrast to the cloudy solutions at $x=0.5$, the increased scattering intensity seen in Figure 6 at $q<0.02$ $\AA^{-1}$ completely disappears. Consequently, the large polymer aggregates are completely dissolved for $x>1$. Second, the SANS curves follow $q^{-1}$ behavior over a wide range of $q$, which is characteristic of rodlike objects. At corresponding concentrations binary aqueous $\mathrm{C}_{12} \mathrm{E}_{5}$ follows roughly $q^{-1}$ behavior as well, but the scattering curves clearly differ from those of the ternary system, the difference becoming apparent in the structural parameters obtained by the fitting procedures. Third, the reasonable fits in Figure 7 obtained with the IFT approach justify the modeling by elongated particles in both the binary and ternary mixtures. Small deviations at the lowest $q$ reflect flexibility of elongated objects or the presence of significantly larger aggregates which are not taken into account by IFT. Fourth, Figure 8 indicates that the aggregates in the ternary system possess a smaller cross-section than the micelles in the binary system.

The scattering data were fitted to the models of stiff and flexible cylinders (Figure 9). The choice of the model of a stiff cylinder is justified by distinctive -1 scaling at the intermediate $q$-range and by the successful application of model independent IFT analysis. As this model can be an oversimplification and as the oil swollen surfactant micelles are known to be wormlike, we applied the flexible cylinder model as well. The flexible cylinder model gives a visually better fit at lowest $q$ values (Figure 9), but this agreement does not improve the overall accuracy of the fit, considering the resulting $\chi^{2}$ values $\left(\chi^{2}=\right.$ 2.44 for the stiff cylinder model and 2.2 for the flexible cylinder model). As described above, the parameters obtained are similar as well. It is also noteworthy that the persistence length of PBS$\operatorname{PFP}\left(\mathrm{C}_{12} \mathrm{E}_{5}\right)_{2.0}$ is actually larger than the overall length of PBSPFP $(<20 \mathrm{~nm})$, a similar result as has been reported for the $\mathrm{PPP}-\mathrm{C}_{i} \mathrm{E}_{j}$ system. ${ }^{35}$

Furthermore, the data suggest that the aggregates in the ternary system are thinner than the pure surfactant micelles indicating that they do not consist of well-defined $\mathrm{C}_{12} \mathrm{E}_{5}$ micelles with a PBS-PFP core. We find that this is plausible, because there are only a very few surfactants per repeat unit $(1-2)$. Therefore we believe that $\mathrm{C}_{12} \mathrm{E}_{5}$ will mainly aggregate with the polymer rather than form micelles and suggest that there is a noncooperative binding between $\mathrm{PBS}-\mathrm{PFP}$ and $\mathrm{C}_{12} \mathrm{E}_{5}$. Fiber aggregates of PPP within surfactant micelles have been found elsewhere. ${ }^{35}$ However, in that work, the mass ratio of surfactant over monomer unit was 10, i.e., much higher than in Regime II.

Regime III, $4 \leq x \leq 15$ : Interacting Micelles and Cooperative Binding. As shown in Figures 10-12, an interference maximum at $\sim 0.015 \AA^{-1}$ is seen for the ternary $\mathrm{D}_{2} \mathrm{O}-\mathrm{PBS}-\mathrm{PFP}\left(\mathrm{C}_{12} \mathrm{E}_{5}\right)_{x}$ for $x \geq 4$. This peak corresponds to the maximum of the structure factor of the ordered micellar system. Upon dilution, the interference maximum shifts predictably toward lower $q$, and remains observable down to $\sim 1.25 \times 10^{-4} \mathrm{M}$. Essentially the same behavior is observed for all $x \geq 4$. We observe scaling $q_{\text {max }} \sim c^{1 / 3}$ indicating 3D packing. This scaling behavior differs from that of aqueous poly(sodium $p$-phenylenesulfonate) ${ }^{10}$ and MBL-PPV ${ }^{11}$ which show an interference maximum scaling $q_{\max } \sim c^{1 / 2}$.

We note that the $\mathrm{H}_{1}$ phase of the binary system is formed only when the surfactant fraction is as high as $35 \mathrm{wt} \%{ }^{32}$ Therefore, the observed ordering in the considered dilute solutions $(\sim 1 \mathrm{wt} \%)$ is certainly not caused by steric effects but rather by the electrostatic repulsive interactions induced by the charged PBS-PFP molecules. This ordering should not be a surprise as the counterion sensitive order and a reflection at 
low $q$ due to electrostatic repulsion have been reported also for example for aqueous $\mathrm{PPP}^{8-10}$ and MBL-PPV ${ }^{11}$ polyelectrolytes.

A simple structure that could be considered for Regime III is that where the polymer is included in the hydrocarbon core of the $\mathrm{C}_{12} \mathrm{E}_{5}$ micelle, similar to the wormlike micelles in water$\mathrm{C}_{12} \mathrm{E}_{5}$ - decane ${ }^{30}$ or water-alkyl-substituted PPP $-\mathrm{C}_{i} \mathrm{E}_{j}^{35}$ systems. Nevertheless, in this case the charges would be rather screened by the outer part of the micelle, thus diminishing the intermicellar repulsion, which is contrary to our observation. A further argument against this structure is that the polymersurfactant aggregates observed in Regime II are thinner than the surfactant micelles. Another possibility for PBS-PFP is to be located at the outer surface of the micelle. This would better explain electrostatic repulsion between the micelles and be in agreement with the observed reflection. A rigorous answer cannot be given at present.

Floating Aggregate Layer at the Air-Water Interface. A natural application of the aqueous $\pi$-conjugated system is the controlled formation of Langmuir-Blodgett films from an aqueous subphase. Nondissolved PBS-PFP does not allow film formation but when surfactant is added, films on both hydrophobic and hydrophilic glass show a similar PL spectrum of PBS-PFP (Figure 13) suggesting that not only surfactant but also PBS-PFP has been transferred onto the surface. The blue shift in PL suggests that the PBS-PFP chains are separated, which is plausible assuming that the films are very thin. The PL intensity from the film on hydrophobic glass is considerably weaker than that from the otherwise identically dipped hydrophilic glass, which indicates in turn that the polymer-containing aggregates are attached much better on the hydrophilic than the highly hydrophobic surface. The observation of a floating layer of PBS- $\operatorname{PFP}\left(\mathrm{C}_{12} \mathrm{E}_{5}\right)_{x}$ is in accordance with the corresponding layer of alkyl-substituted $\mathrm{PPP}-\mathrm{C}_{i} \mathrm{E}_{j} .{ }^{18}$

\section{Conclusions}

In summary, the solubilization of PBS-PFP polymer by $\mathrm{C}_{12} \mathrm{E}_{5}$ surfactant in water has been studied. The dissolution of the polymer was initially suggested by the visual transparency and a blue shift in the PL spectrum upon mixing the constituents. As indicated by this consideration, the polymer itself is not water soluble but can be solubilized by aqueous $\mathrm{C}_{12} \mathrm{E}_{5}$. The phase behavior of $\mathrm{D}_{2} \mathrm{O}-\mathrm{PBS}-\mathrm{PFP}\left(\mathrm{C}_{12} \mathrm{E}_{5}\right)_{x}$ was then detailed by using the PL, surface tension, static contact angle, $(\pi-A)$ isotherms, and SANS. A feasibility study of the film formation was also realized.

The $\mathrm{D}_{2} \mathrm{O}-\mathrm{PBS}-\mathrm{PFP}\left(\mathrm{C}_{12} \mathrm{E}_{5}\right)_{x}$ system was specifically considered when the surfactant concentration was above the CMC of aqueous $\mathrm{C}_{12} \mathrm{E}_{5}$ at the temperature $\left(20^{\circ} \mathrm{C}\right)$ and concentration which correspond to the isotropic liquid $\mathrm{L}_{1}$ phase regime of the binary $\mathrm{D}_{2} \mathrm{O}-\mathrm{C}_{12} \mathrm{E}_{5}$ system. Under these conditions, three ternary phase regimes were observed. First, the cloudy phase is seen for $x \leq 0.5$ (Regime I, partial solubilization) indicating partial dissolution of the polymer. Second, the $\mathrm{D}_{2} \mathrm{O}-\mathrm{PBS}-\mathrm{PFP}-$ $\left(\mathrm{C}_{12} \mathrm{E}_{5}\right)_{x}$ solution turns homogeneous for $x \geq 1$ (Regime II, dissolved aggregates). The $q^{-1}$ behavior of all the measured SANS curves indicates rodlike aggregates for $x=1-2$, resembling the wormlike micelles of binary surfactant solutions. However, the scattering characteristics of the ternary system differ from those of the binary ones and the persistence length was found to be larger (up to $30 \mathrm{~nm}$ ). Fitted data to the model of stiff and flexible cylinders indicate rodlike conformation for which the ratio between length and persistence length is $<3$. Interestingly, the aggregates in the ternary system were found to be less flexible and thinner than the micelles in the binary ones. Third, for $x=4-15$ (Regime III, interacting micelles), the SANS curve shows an interference peak at $q \sim 0.015 \AA^{-1}$. This ordering is suggested to be due to the repulsion between the charged polymers attached to or incorporated into the micelles.

Altogether these results show that a high amount (milligrams per milliliter) of otherwise insoluble polyfluorene can be solubilized in water by using $\mathrm{C}_{12} \mathrm{E}_{5}$ via complicated aggregate formation. These aggregates form a floating layer at the airwater interface and can be transferred onto the hydrophilic substrate with use of Langmuir dipping.

Acknowledgment. This work has been funded by One North East (UK) UIC Nanotechnology Grant. L.A. thanks the Széchenyi István Scholarship Foundation for support. M.K. and L.A. thank the European Commission for support under the 6th Framework Program through the Key Action: Strengthening the European Research Area, Research Infrastructures (Contract No. RII3-CT-2003-505925).

\section{References and Notes}

(1) Heeger, P. S.; Heeger, A. J. Proc. Natl. Acad. Sci. U.S.A. 1999 , 96, 12219-12221.

(2) Chen, L.; McBranch, D. W.; Wang, H.-L.; Helgeson, R.; Wudl, F.; Whitten, D. G. Proc. Natl. Acad. Sci. U.S.A. 1999, 96, 12287-12292.

(3) Sirringhaus, H. Adv. Mater. 2005, 17, 2411-2425.

(4) Breiby, D. W.; Samuelsen, E. J.; Konovalov, O.; Struth, B. Langmuir 2004, 20, 4116-4123.

(5) Bjørnholm, T.; Hassenkam, T.; Reitzel, N. J. Mater. Chem. 1999 9, 1975-1990.

(6) Levitsky, I. A.; Kim, J.; Swager, T. M. Macromolecules 2001, 34, $2315-2319$

(7) Knaapila, M.; Stepanyan, R.; Lyons, B. P.; Torkkeli, M.; Monkman, A. P. Adv. Funct. Mater. 2006, 16, 599-609.

(8) Guilleaume, B.; Blaul, J.; Wittemann, M.; Rehahn, M.; Ballauff, M. J. Phys.: Condens. Matter 2000, 12, A245-A251.

(9) Guilleaume, B.; Blaul, J.; Ballauff, M.; Wittemann, M.; Rehahn, M.; Goerigk, G. Eur. Phys. J. E 2002, 8, 299-309.

(10) Zaroslov, Yu. D.; Gordeliy, V. I; Kuklin, A. I; Islamov, A. H.; Philippova, O. E.; Khokhlov, A. R.; Wegner, G. Macromolecules 2002, 35, 4466-4471.

(11) Wang, D.; Lal, J.; Moses, D.; Bazan, G. C.; Heeger, A. J. Chem Phys. Lett. 2001, 348, 411-415.

(12) Gaylord, B. S.; Heeger, A. J.; Bazan, G. C. Proc. Natl. Acad. Sci. U.S.A. 2002, 99, 10954-10957.

(13) Ma, W.; Iyer, P. K.; Gong, X.; Liu, B.; Moses, D.; Bazan, G. C.; Heeger, A. J. Adv. Mater. 2005, 17, 274-277.

(14) Burrows, H. D.; Lobo, V. M. M.; Pina, J.; Ramos, M. L.; Seixas de Melo, J.; Valente, A. J. M.; Tapia, M. J.; Pradhan, S.; Scherf, U. Macromolecules 2004, 37, 7425-7427.

(15) Tapia, M. J.; Burrows, H. D.; Valente, A. J. M.; Pradhan, S.; Scherf, U.; Lobo, V. M. M.; Pina, J.; Seixas de Melo, J. J. Phys. Chem. B 2005 109, 19108-19115.

(16) Chen, L.; Xu, S.; McBranch, D.; Whitten, D. J. Am. Chem. Soc. 2000, 122, 9302-9303

(17) Chen, L.; Xu, S.; McBranch, D.; Whitten, D. Enhanced photophysics of conjugated polymers, complex with surfactants, their manufacture and fluorescent properties. U.S. Patent Application 6569952, 2003, 12 pp.

(18) Fütterer, T.; Hellweg, T.; Findenegg, G. H.; Frahn, J.; Schlüter, A D.; Böttcher, C. Langmuir 2003, 19, 6537-6544.

(19) Fütterer, T.; Hellweg, T.; Findenegg, G. H. Particle characterization by scattering methods in systems containing different types of aggregates: Aggregation of an amphiphilic poly( $p$-phenylene) in micellar surfactant. In ACS Symposioum Series: Mesoscale Phenomena in Fluid Systems; Case, F., Alexandris, P., Eds.; American Chemical Society: Washington, DC, 2003; Vol. 861, p 117.

(20) Knaapila, M.; Stepanyan, R.; Horsburgh, L. E.; Monkman, A. P.; Serimaa, R.; Ikkala, O.; Subbotin, A.; Torkkeli, M.; ten Brinke, G. J. Phys. Chem. B 2003, 107, 14199-14203.

(21) Hellweg, T. Curr. Opin. Colloid Interface Sci. 2002, 7, 50-56.

(22) Holmberg, K.; Jönsson, B.; Kronberg, B.; Lindman, B. Surfactants and Polymers in Aqueous Solutions, 2nd ed.; Wiley: Chichester, UK, 2003.

(23) Sprunt, S.; Zhang, C. Y.; Litster, J. D. J. Chem. Phys. 1995, 103 , $10325-10331$.

(24) Salamat, G.; de Vries, R.; Kaler, E. W.; Satija, S.; Sung, L. Langmuir 2000, 16, 102-107. 
(25) Maccarini, M.; Briganti, G. J. Phys. Chem. A 2000, 104, 1145111458

(26) Stoyanov, S. D.; Rehage, H.; Paunov, V. N. Phys. Rev. Lett. 2003, 91, 086102 .

(27) D'Arrigo, G.; Briganti, G.; Maccarini, M. J. Phys. Chem. B 2006, $110,4612-4620$.

(28) Fritz, G.; Scherf, G.; Glatter, O. J. Phys. Chem. B 2000, 104, 34633470 .

(29) Lichterfeld, F.; Schmeling, T.; Strey, R. J. Phys. Chem. 1986, 90, 5762-5766.

(30) Menge, U.; Lang, P.; Findenegg, G. H.; Strunz, P. J. Phys. Chem. B 2003, 107, 1316-1320.

(31) Kato, T.; Anzai, S.; Seimiya, T. J. Phys. Chem. 1990, 94, 72557259.

(32) Strey, R.; Schomäcker, R.; Roux, D.; Nallet, F.; Olsson, U. J. Chem. Soc., Faraday Trans. 1990, 86, 2253-2261.

(33) Hellweg, T.; von Klitzing, R. Phys. A 2000, 283, 349-358.

(34) Fütterer, T.; Hellweg, T.; Findenegg, G. H.; Frahn, J.; Schlüter, A. D. Macromolecules 2005, 38, 7443-7450.

(35) Fütterer, T.; Hellweg, T.; Findenegg, G. H.; Frahn, J.; Schlüter, A. D. Macromolecules 2005, 38, 7451-7455.

(36) Burrows, H. D.; Lobo, V. M. M.; Pina, J.; Ramos, M. L.; Seixas de Melo, J.; Valente, A. J. M.; Tapia, M. J.; Pradhan, S.; Scherf, U.; Hintschich, S. I.; Rothe, C.; Monkman, A. P. Colloids Surf. A 2005, 270$271,61-66$

(37) Tiddy, G. J. T. Phys. Rep. 1980, 57, 1-46.

(38) Dutschk, V.; Sabbatovskiy, K. G.; Stolz, M.; Grundke, K.; Rudoy,

V. M. J. Colloid Interface Sci. 2003, 267, 456-462.

(39) Rosta, L. Appl. Phys. A 2002, 74, S52.

(40) Stuhrmann, H. B.; Burkhardt, N.; Dietrich, G.; Jünemann, R.; Meerwinck, W.; Schmitt, M.; Wadzack, J.; Willumeit, R.; Zhao, J.; Nierhaus, K. H. Nucl. Instrum. Methods Phys. Res., Sect. A 1995, A356, 124-132. (41) Wignall, G. D.; Bates, F. S. J. Appl. Crystallogr. 1987, 20, 28-
(42) Glatter, O. J. Appl. Crystallogr. 1977, 10, 415-421.

(43) Pedersen, J. S.; Posselt, D.; Mortensen, K. J. Appl. Crystallogr. 1990, 23, 321-333.

(44) Pedersen, J. S.; Schurtenberger, P. J. Appl. Crystallogr. 1996, 29, 646-661.

(45) Pedersen, J. S.; Schurtenberger, P. Macromolecules 1996, 29, $7602-7612$

(46) Jerke, G.; Pedersen, J. S.; Egelhaaf, S. U.; Schurtenberger, P. Phys. Rev. E 1997, 56, 5772-5788.

(47) Holmes, M. C.; Reynolds, D. J.; Boden, N. J. Phys. Chem. 1987 91, 5257-5262.

(48) Iijima, H.; Kato, T.; Yoshida, H.; Imai, M. J. Phys. Chem. B 1998, 102, 990-995.

(49) Fytas, G.; Nothofer, H. G.; Scherf, U.; Vlassopoulos, D.; Meier, G. Macromolecules 2002, 35, 481-488.

(50) Knaapila, M.; Stepanyan, R.; Torkkeli, M.; Lyons, B. P.; Ikonen, T. P.; Almásy, L.; Foreman, J. P.; Serimaa, R.; Güntner, R.; Scherf, U.; Monkman, A. P. Phys. Rev. E 2005, 71, 041802.

(51) Chen, S. H.; Sheu, E. Y.; Kalus, J.; Hoffmann, H. J. Appl. Crystallogr. 1988, 21, 751-769.

(52) Boden, N. Statistical Thermodynamics of Amphiphilic SelfAssembly: Structure and Phase Transitions in Micellar Solutions. In Micelles, Membranes, Microemulsions, and Monolayers; Gelbart, W. M., Ben-Shaul, A., Roux, D., Eds.; Springer: New York, 1994; pp 153-211.

(53) Fletcher, P. D. I.; Nicholls, R. J. Phys. Chem. Chem. Phys. 2000, 2, 361-365.

(54) Schmidt, P. W. Some Fundamental Concepts and Techniques Useful in Small-Angle Scattering Studies of Disordered Solids. In Modern Aspects of Small-Angle Scattering; Brumberger, H., Ed.; Kluwer Academic Publishers: Dordrecht, The Netherlands, 1995; pp 1-56.

(55) Feigin, L. A.; Svergun, D. I. Structure Analysis by Small-Angle $X$-ray and Neutron Scattering; Plenum Press: New York, 1987. 